\title{
Centrifuge Study of the Seismic Response of Municipal Solid Waste Landfill
}

\author{
PENG Ren ${ }^{1, a}$, HOU Yujing ${ }^{2, b}$ and WANG Cun ${ }^{2, c}$ \\ ${ }^{1}$ Department of Civil Engineering, Beihang University, No.37 Xue-Yuan Road, Beijing 100191, \\ China \\ ${ }^{2}$ Department of Geotechnical Engineering, China Institute of Water Resources and Hydropower \\ Research (IWHR), No.20 Che-Gongzhuang West Road, Beijing 100048, China

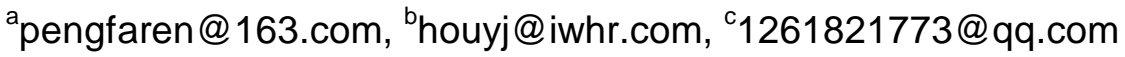

\begin{abstract}
Keywords: municipal solid waste; landfill; centrifuge; seismic response
Abstract. Seismic response of municipal solid waste (MSW) landfill under horizontal and vertical earthquakes has been investigated by dynamic centrifuge testing. The MSW was modelled by mechanically representative model waste. The acceleration response at various depths were recorded and used to investigate the amplification characteristics of a MSW landfill. Vertical settlement was also measured during the shaking event. Post-test observations were compared to the realistic damage that occurs in a landfill under earthquake loading. The results also provide the data for validating the analytical methods of the seismic response of MSW landfill.
\end{abstract}

\section{Introduction}

The main objective of the proper seismic design of municipal solid waste (MSW) landfills is the protection of human health and the environment [1]. Better understanding of seismic behavior of MSW landfills can be used both for design of new landfills and for risk assessing old landfills located in seismic regions.

There have many scholars summed up the failure mode of MSW landfill by earthquake damage survey [2], and many simulations packages such as SHAKE91, D-MOD, QUAD4M and FLAC was used in the seismic analysis of MSW landfills [3]. But real MSW is highly heterogeneous, and the properties constantly changed with decomposition process, so there are many uncertainties involved in the analysis.

Centrifuge model test is an effective approach to study the issues related to geotechnical earthquake engineering. A pioneering study into the seismic behavior of MSW landfill has been carried out by dynamic centrifuge testing [4]. The present studies have only paid attention to horizontal earthquake effects, but the effect of vertical earthquake on the seismic response of MSW landfill is rarely reported.

In this paper, a hydraulic earthquake simulator R500B installed on 450g-ton geotechnical centrifuge of IWHR was used to investigate the seismic response of MSW landfill under horizontal and vertical earthquakes. The shaker can be operated under centrifuge acceleration of $80 \mathrm{~g}$ with maximum $30 \mathrm{~g}$ in horizontal shaking and $20 \mathrm{~g}$ in vertical. It's maximum shaking frequency is $400 \mathrm{~Hz}$, with a payload of $400 \mathrm{~kg}$.

\section{Experimental Scheme}

Test Equipment. The exterior structure of shaking table R500B was shown in Fig.1. Hou [5] presents an introduction of its main feature. The dynamic centrifuge test was performed in an equivalent shear beam (ESB) box of internal dimensions $810 * 345 * 500 \mathrm{~mm}$. The design and performance of the ESB box was described by Hou [5].

Modelling Design. MSW is usually highly heterogeneous and variable in its content. Thus the use of real MSW in experiments has many uncertainties, even the health and safety are under threat if handling real MSW under laboratory conditions. A model waste, whose mechanic properties closely match to those of a typical MSW, was developed and used in this model test $[6,7]$. 
The seismic response of a landfill can vary significantly due to variations of waste properties, fill heights, site conditions, and design rock motions [3]. This test was mainly designed to study the propagation of seismic wave in waste body. The model was simplified, especially did not consider the effect of composite liner system and cover system on the seismic response of MSW landfill, as shown in Fig.2. Accelerometers in the horizontal and vertical direction were placed at the locations shown in Fig.2. Two laser displacement sensors were mounted on the top of the container to measure the model waste settlement. Camera can be used to consistently observe the deformation of the slope.

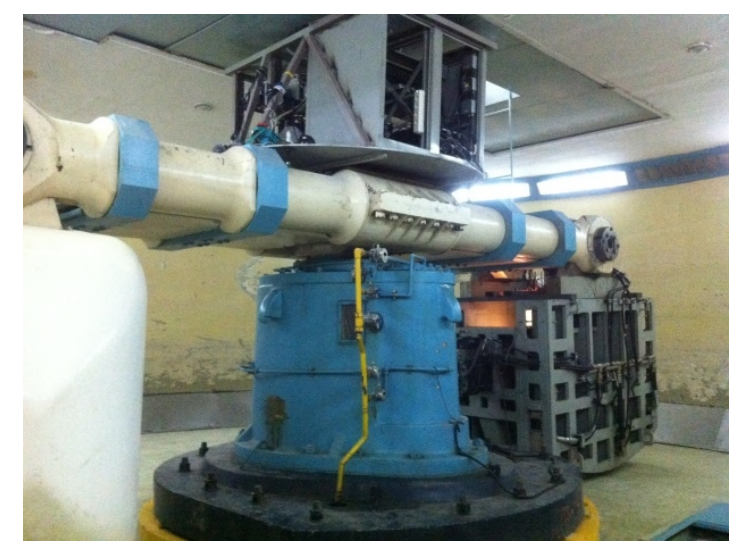

Fig. 1 R500B used for geotechnical centrifuge

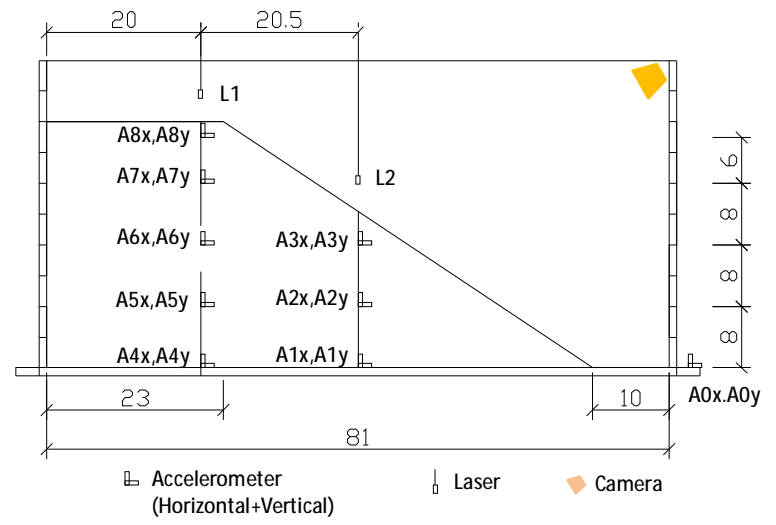

Fig. 2 Model configuration (Dimensions: $\mathrm{cm}$, in model scale)

Vibration Signals. The input signals can be expressed as follows:

$$
A(t)=\frac{A_{p}}{2}\left[1-\cos 2 \pi\left(\frac{t_{T}}{T}\right)\right] \cdot \sin (2 \pi f t)
$$

Where $A_{\mathrm{p}}$ is peak acceleration, $f$ is vibration frequency, $\mathrm{T}$ is duration of vibration. The peak acceleration of target signal in this test was 30 time's earth's gravity $(30 \mathrm{~g})$ and $20 \mathrm{~g}$ in the horizontal and vertical direction, respectively. Vibration frequency $f$ is equal to $70 \mathrm{~Hz}$, and $\mathrm{T}$ is equal to $0.6 \mathrm{~s}$.

The dynamic centrifuge test was performed at $30 \mathrm{~g}$. At $30 \mathrm{~g}$, two earthquakes were applied to the model. Table 1 provides the details of the applied earthquakes.

Table 1. Model earthquakes applied in the test (prototype scale)

\begin{tabular}{|l|l|l|l|l|l|}
\hline Test number & \multicolumn{2}{|l|}{ Earthquake } & $\begin{array}{l}\text { Main } \\
\text { Frequency (Hz) }\end{array}$ & Duration (s) & $\begin{array}{l}\text { Maximum acceleration } \\
\text { of Base (g) }\end{array}$ \\
\hline \multirow{3}{*}{ T1 } & \multicolumn{2}{|l|}{} & 2.33 & 18 & 0.489 \\
\cline { 2 - 6 } & \multirow{2}{*}{ E2 } & Horizontal & 2.33 & 18 & 0.524 \\
\cline { 2 - 6 } & & Vertical & 2.33 & 18 & 0.243 \\
\hline
\end{tabular}




\section{Experimental Results}

It is the emphasis how did the acceleration sensors along the longitudinal of model response to the input earthquakes. Fig. 3 shows the acceleration signals during Earthquake 2. All acceleration signals are given in prototype scale.

The magnification coefficient of the acceleration response along model height can be shown in Fig. 4. The amplificatory coefficient of acceleration (ACA) is the ratio between peak horizontal accelerations and peak horizontal ground accelerations (The same in the vertical direction). The ACA ranged on a scale of 1 to 1.5, and it firstly increased and then decreased along model height near the side slope. On the top surface, The ACA near the top of slope was generally larger than at the side slope. The vertical ACA near the top of slope increases obviously, and the maximum ACA was 2.1.

The earthquakes have raised a large additional vertical settlement, as shown in Fig.5. When vibration generate in the horizontal and vertical direction simultaneously, sedimentation effects become even more obvious. It could be caused by additional vertical forces that compress the waste.

The MSW landfill did not whole collapse under earthquake loading, but a crack in the top surface of the model waste was observed, and down-slope movement appeared, as shown in Fig.6. The failure mode is consistent with the case histories reporting the performance of MSW landfills in the past earthquakes suggested that overall performance of landfills has been reasonably good [2].
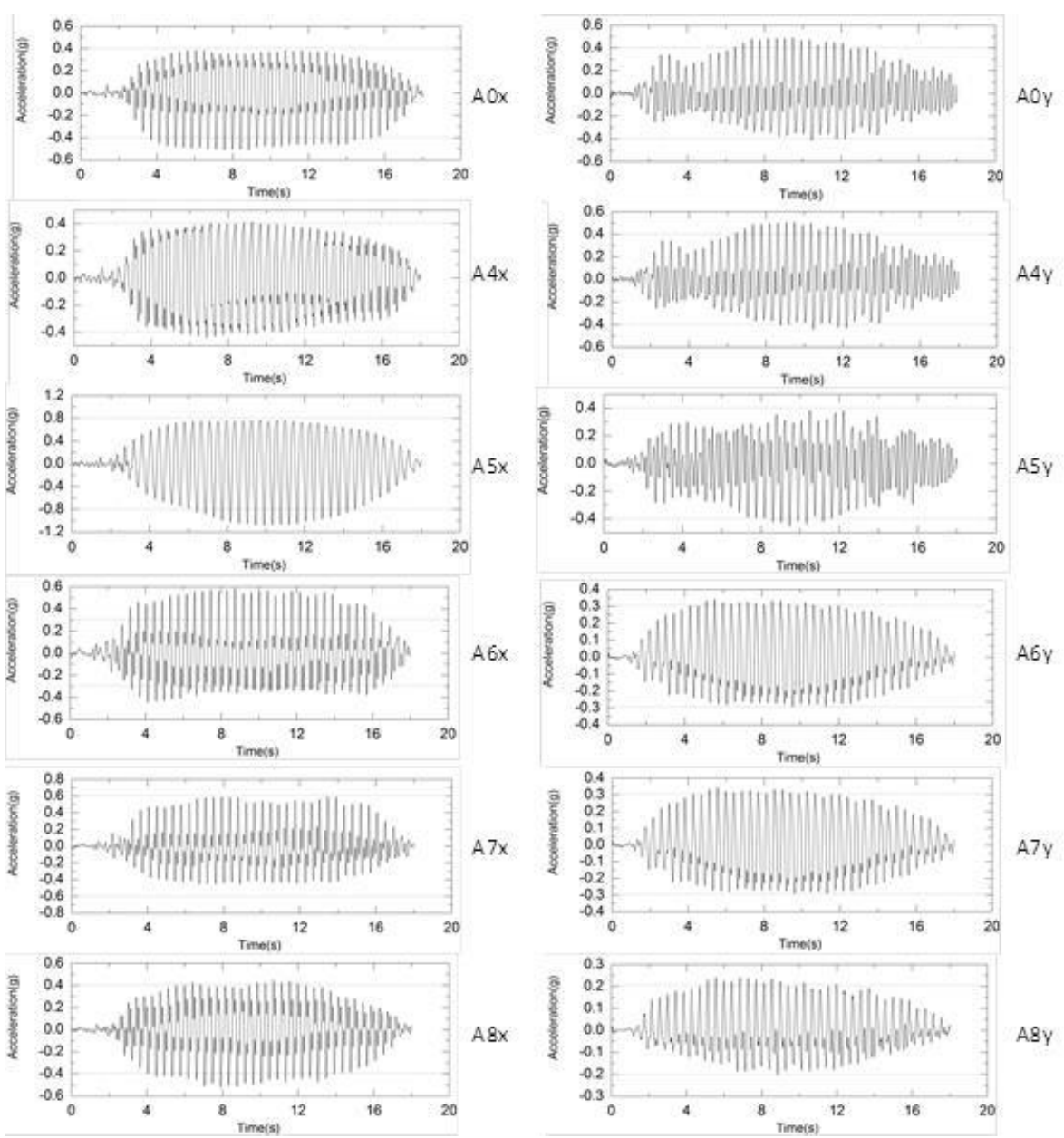

Fig.3 Variation of acceleration with time under E2 


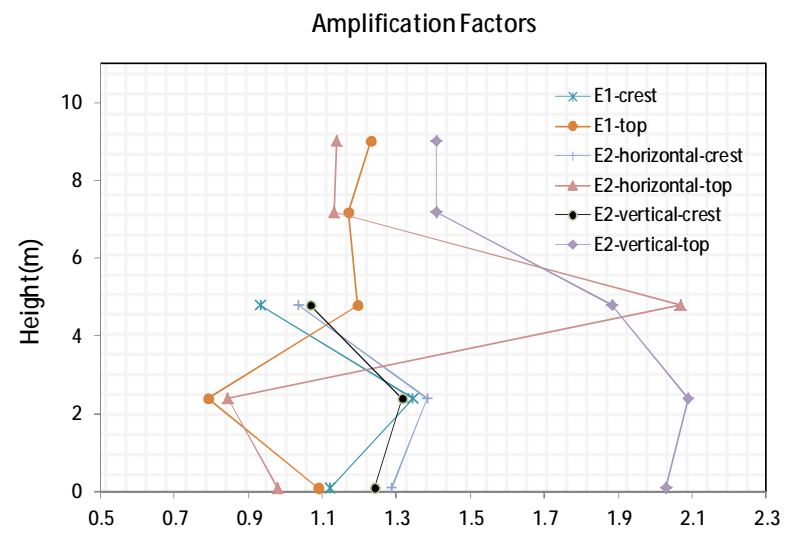

Fig.4 Amplification factors of acceleration under E1, E2
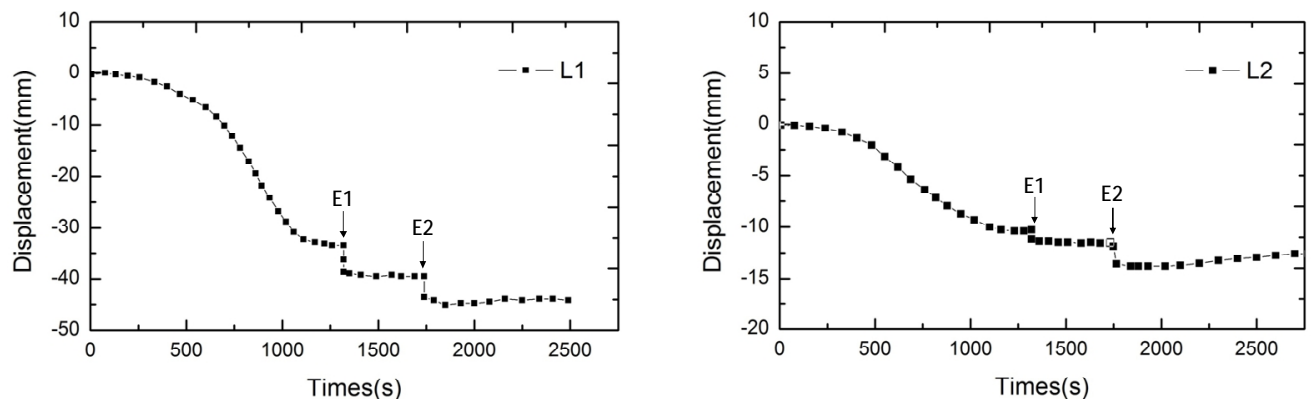

Fig.5 Model waste settlement of L1 and L2
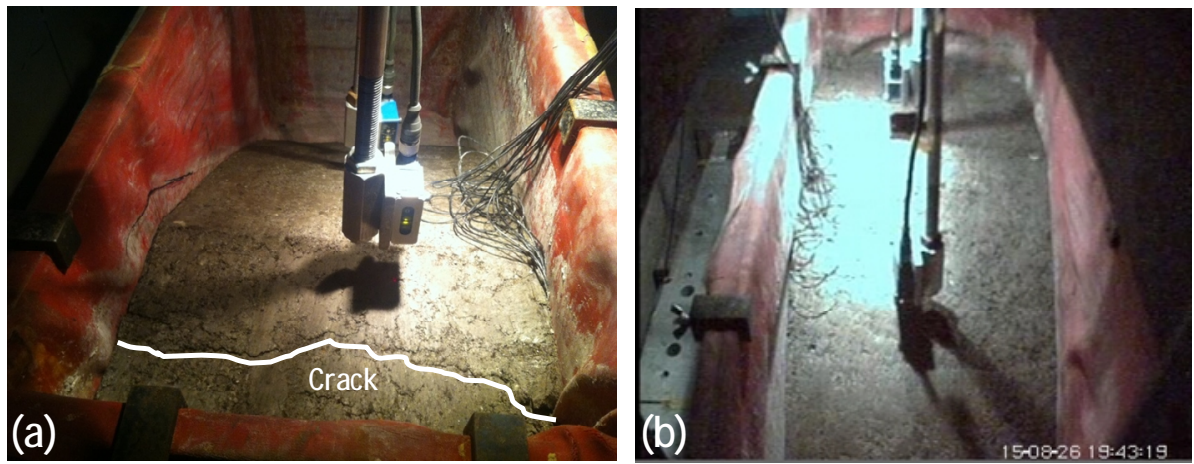

Fig.6 Post-test observations

\section{Conclusions}

The amplificatory coefficient of acceleration ranged on a scale of 1 to 1.5 , that closely related to the location. It is necessary to pay attention to the results that the vertical acceleration amplification coefficient near the top of slope increases obviously. A large additional vertical settlement will be induced by earthquake loading. Especially the vertical earthquake, lead to a comparatively obvious compressing settlement. The post-test observations indicate that the general performance of MSW landfill during earthquakes is good, but cracking and down-slope movement may appear during the shaking event.

\section{Acknowledgements}

This work was supported by the National Basic Research Program (973) of China (2012CB719803, 2014CB047001). 


\section{References}

[1] V. Zania, Y. Tsompanakis and P.N. Psarropoulos: Journal of Earthquake Engineering. Vol.12 (2008), 312-340.

[2] N. Matasovic, E. Kavazanjian and R.L. Anderson: Earthquake Spectra, Vol.14 (1998), 319-334.

[3] P.S.S e Pinto: Static and seismic analysis of solid waste landfills (Springer Berlin Heidelberg, Germany 2010).

[4] N.I. Thusyanthan, S.P.G. Madabhushi and S. Singh: Geotextiles and Geomembranes. Vol.25 (2007), 78-95.

[5] Y.J. Hou: Journal of China Institute of Water Resources and Hydropower Research, Vol 4(2006), $15-22$.

[6] B. Zhu, C.B. Yang, L. Wang and Y.M. Chen, in: the 1st China National Symposium on Coupled Phenomena in Geo-materials and Environmental Geotechnics, edited by Y.M. Chen, Hangzhou, China, in Chinese.

[7] R. Peng, Y.J. Hou, L.T. Zhan and Y.P. Yao: Int. J. Environ. Res. Public Health, Vol.13 (2016), 126. 